\title{
Yarı Kurak Ekolojik Şartlarda Farklı Ana Materyal Üzerinde Oluşan Genç Toprakların Ayrışma Oranları ve Pedolojik Gelişimleri
}

\author{
Oğuzhan TOPCU, Orhan DENGIZ* \\ Ondokuz Mayıs Üniversitesi, Ziraat Fakültesi, Toprak Bilimi ve Bitki Besleme Bölümü, Samsun, TÜRKIYYE
}

\begin{tabular}{ll}
\hline \multicolumn{1}{c}{ Geliş Tarihi/Received: 21.09 .2021} & Kabul Tarihi/Accepted: 27.11 .2021 \\
\hline ORCID ID (Yazar strasına göre / by author order) \\
(1D) orcid.org/0000-0002-5966-3250 (D) orcid.org/0000-0002-0458-6016 \\
"Sorumlu Yazar/Corresponding Author: odengiz@omu.edu.tr
\end{tabular}

Öz: Bu çalışmada, aynı iklim koşulları altında, farklı jeolojik ana materyal üzerinde oluşmuş genç toprakların ayrışma oranlarının belirlenmesi ve ana materyalin toprak oluşumu üzerine olan etkilerinin incelenmesi amaçlanmıștır. Çalıșma kapsamında, Türkiye'nin Ege Bölgesi’nde yer alan Afyonkarahisar ilinin Sandıklı ilçesi civarında dağılım gösteren magmatik, metamorfik ve sedimanter ana materyal üzerinde oluşmuş üç adet genç toprağa ait jeo-kimyasal, fiziko-kimyasal, primer ve sekonder mineralojik özellikler profil bazlı olarak tespit edilerek, ayrışma indisleri hesaplanmıştır. Çalışma sonunda, farklı ana materyallerin aynı iklim koşullarında toprak genesisi üzerine olan etkisi ortaya konulmuş, ayrışma indisleri (kimyasal alterasyon indeksi, kimyasal ayrışma indeksi ve $\mathrm{Baz} / \mathrm{R}_{2} \mathrm{O}_{3}$ oran1)'yle toprak genesisi sayısal olarak ifade edilmiştir. $\mathrm{Bu}$ şekilde, toprak oluşumunun ölçüm derecesi olarak değerlendirilen mineralojik, fiziko-kimyasal ve jeo-kimyasal özellikler parametrik olarak ilişkilendirilmiştir. Elde edilen sonuçlara göre; yüzey altı tanı horizonları saptanmamış olmaları nedeniyle, incelenen topraklar pedolojik gelişimlerini tamamlamadıklarından Entisol olarak sınıflandırılmıştır. Toprakların ayrışma oranları yönünden karşılaştıııldığında, farklı ana materyaller üzerinde yer alan her üç toprakta oluşumlarının başlangıç aşamasında olup, topraklar fiziko-kimyasal, jeo-kimyasal ve minerolojik özellikleri yönünden halen ana materyallerinin etkisi altında oldukları belirlenmiştir.

Anahtar Kelimeler: Genç topraklar, ayrışma oranları, kil minerolojisi, yarı kurak koşullar, pedoloji

\section{Pedological Development and Weathering Rates of Young Soils Formed on Different Parent Materials under Semi-Arid Ecological Condition}

\begin{abstract}
In this study, it is aimed to determine the weathering rates of young soils formed under the same climatic conditions on different geological parent material and to examine the effects of the parent material on soil formation. Within the scope of the study, geo-chemical, physico-chemical, primary, and secondary mineralogical properties of three young soils, formed on magmatic, metamorphic, and sedimentary parent material, distributed around the Sandıkl district of Afyonkarahisar province in the Aegean Region of Turkey, were determined on profile-base and the dissociation indices were calculated. At the end of the study, the effect of different parent materials on soil genesis under the same climatic conditions was revealed, and weathering indices namely the Chemical Index of Alteration (CIA), Chemical Index of Weathering (CIW), and Base/ $\mathrm{R}_{2} \mathrm{O}_{3}$ ratio were calculated. In this way, mineralogical, physico-chemical and geo-chemical properties, which are considered as the measurement degree of soil formation, are correlated parametrically. According to the results obtained; since sub-surface diagnostic horizons were not detected, the investigated soils were classified as Entisol since they did not complete their pedological development. When compared to the decomposition rates of soils, all three soils located on different parent materials are at the initial stage of their formation and it has been determined that soils are still under the influence of their parent materials in terms of their physico-chemical, geo-chemical and mineralogical properties.
\end{abstract}




\section{Giriş}

Herhangi bir bölge içerisinde meydana gelen toprak oluşumu, o bölgedeki iklim ve canlıların farklı topoğrafik şartlar ve belirli bir zaman içerisinde ana materyal üzerinde yapmış olduğu etkidir (Dengiz ve Başkan, 2010). Hatta, söz konusu toprakların profil içerisinde meydana gelen ayrışma, taşınma, yıkanma, yer değiştirme ve birikme gibi olaylar ile birlikte toprak yapan faktörler, o ekolojik koşullar altında oluşan biyolojik, fiziksel ve kimyasal tepkimeler ile topraklara kendilerine özgün karakterler kazandırırlar (Usul ve Dengiz, 2010).

Toprak, yeryüzünü ince bir tabaka halinde saran, kayaçların ve minerallerin parçalanması ve ayrışması ile oluşan ayrışma ürünleri ve bir takım organik madde bulunduran kısımdır. Jeny (1941), toprakların, toprak oluşumunda rol oynayan beş farklı çevresel unsurlarının (ana materyal, topoğrafya, iklim, canlılar ve zaman) farklı katk1 oranlarında meydan geldiklerini belirtmiştir. Dolayısıyla, yeryüzü üzerinde topraklar, toprak oluşturan çevresel unsurlar ve toprak oluşum süreçleri doğrultusunda zamana bağlı birbirinden farklı özellikler kazanırlar ve değişim gösterirler (Aydemir ve ark., 2001; Tunçay ve Dengiz, 2020). Bu değişimler içerisinde elementlerin jeo-kimyasal ve mineral parçalanma varyasyonları, bitki, su ve toprak sistemlerindeki döngülerine benzer konuları içerisinde barındırır. Toprakların ayrışma oranları, toprakların karakteristiklerindeki farkl1lıklar ve çevre şartlarındaki değişmeler nedeniyle çok değişkenlik gösterir. Bu nedenle, toprağın oluşumu için geçen süreç ve çevresel şartlar, toprağın özelliğini etkiler ve toprakların ayrışma oranlarını belirler. $\mathrm{Bu}$ etkiler, süreç içerisinde kimyasal, mineralojik ve fiziksel özelliklerinin değişimine veya pedolojik gelişmenin yansıması olan horizonların farklılaşmasına neden olurlar. Toprak oluşumunun erken safhalarında, toprakların kimyasal yapılarını ana materyal belirlerken, olgun toprakların kimyasal özellikleri ayrışma ortamının etkileri belirler (Şenol ve ark., 2018). Zaman içerinde topoğrafya, vejetasyon ve iklimin etkisiyle ortaya çıkan pedojenik süreçler ile toprak kütlesi, ana materyale göre farkl1lık gösterir (Mutlu, 2010). $\mathrm{Bu}$ farklılık, en başta elementlerin toprak profili içerisinde yeniden dağılımı ve horizonlaşmanın yanı sıra bu dağılıma bağlı olarak da toprak tiplerinin farklılaşmasına neden olur (Jenkins ve Jones, 1980). Fakat toprağın oluşumu için süreç aynı olsa dahi, diğer toprak oluşturan unsurların etkisi altında toprak morfolojisi ve fiziko-kimyasal özellikler değişiklik gösterebilir (Mutlu, 2010; Dengiz ve ark., 2013).

Topraklarda ayrışma oranlarının belirlenmesi, oluşum sürecinde toprakların gelişim proseslerinin belirlenmesinde temel bir yaklaşımdır (Schoetzl ve ark., 1994; Özaytekin ve Karakaplan, 2012; Saricaoğlu ve ark., 2021). Topraklarda ayrışmanın belirlenmesinde en çok kullanılan metotlardan birisi ayrışma indisleridir. Ayrışma indisleri genel anlamda ana elementlerin oksitlerinin molekül niceliklerinin kullanıldığı farklı yöntemler ile belirlenir. Toprak minerallerinin yüzeyinde oluşan kimyasal ayrışma işlemleri dinamik vejeo-kimyasal bir prosestir. Bu nedenle parçalanma hızı, uzun bir dönem boyunca bitki besin elementi alımını ve toprağın verimliliğinin belirlenmesi için çok önemlidir (Duan ve ark., 2002; Özaytekin ve Dedeoğlu, 2021). Bu yöntemlerden birisi de elementel yer değiştirmelerde bazik katyon konsantrasyon değişimidir. Özellikle topraktan bazik katyonlar, bitkilerce alınımı, yıkanma ve toprağın minerallerinin ayrışmasındaki birincil sistemlerin etkileriyle oluşan yer değiştirmeler ile yönlendirilmektedir (Hodson ve ark., 1998).

Çalışma alanı olan Afyonkarahisar-Sandıklı bölgesinde metamorfik, sedimenter ve magmatik jeolojik birimlerin dar bir alanda bir arada bulunduğu ender yerlerden birisidir. Bu birimler bu alanda birbirlerinden net bir şekilde ayrilarak tanımlanabilirler. Bu şekilde Türkiye'nin bir başka bölgesinde belirtilen üç birimin yakın ölçekte bir arada bulunduğu alan yoktur. Dolayısıyla, belirtilen bölge kısa mesafede farklı jeolojik ana materyallere sahiptir. Bu çalışmada; toprak oluşum süreçlerinden iklim faktörünün hemen hemen aynı olduğu topraklarda, farklı jeolojik ana materyallerin benzer iklim, topoğrafya ve bitki örtüsü faktörleri altında farklı tür ana materyallerin mineralojik ve kimyasal özelikleri ile ve ayrışma indisleri vasıtası ile sayısal olarak ortaya konulması amaçlanmıştır.

\section{Materyal ve Yöntem}

\subsection{Araştırma alanı tanımı ve bazı coğrafik özellikleri}

Araştırmada çalışma alanı; Afyon il sınırları içerisindeki Sandıklı İlçesi ve çevresini içeren yaklaşık $750 \mathrm{~km}^{2}$ 'lik bir alanı kaplamakta olup, 1:25.000 ölçekli topoğrafik paftalar olan K24-d3, K24-c4, L24-a2, L24-b1, L24-a3 ve L24-b4 içerisine girmektedir (Şekil 1).

Sandıklı ilçesi ve civarında yer alan alanlar 1000-1200 m yüksekliğe sahip iken doğu, kuzeydoğu ve güneydoğu yönlerinde bu yükseltiler daha da artmaktadır. Yükselti artışına bağlı olarak topoğrafik özelliklerde değişmekte ve eğim artış göstermektedir. Sandıklı ilçesi ve yakın çevresine ait arazilerin temel coğrafi özelliklerinin ortaya konulması amacıyla alanın sayısal eş yükselti ve DEM haritası üretilerek eğim ve yükseklik haritaları elde edilmiştir Çalışma alanı deniz 
seviyesinden yaklaşık $964 \mathrm{~m}$ ile $1065 \mathrm{~m}$ arasında yer almakta olup, kuzeydoğu ve güneydoğuya doğru eğim giderek artış göstererek dikleşmektedir (Şekil 2).

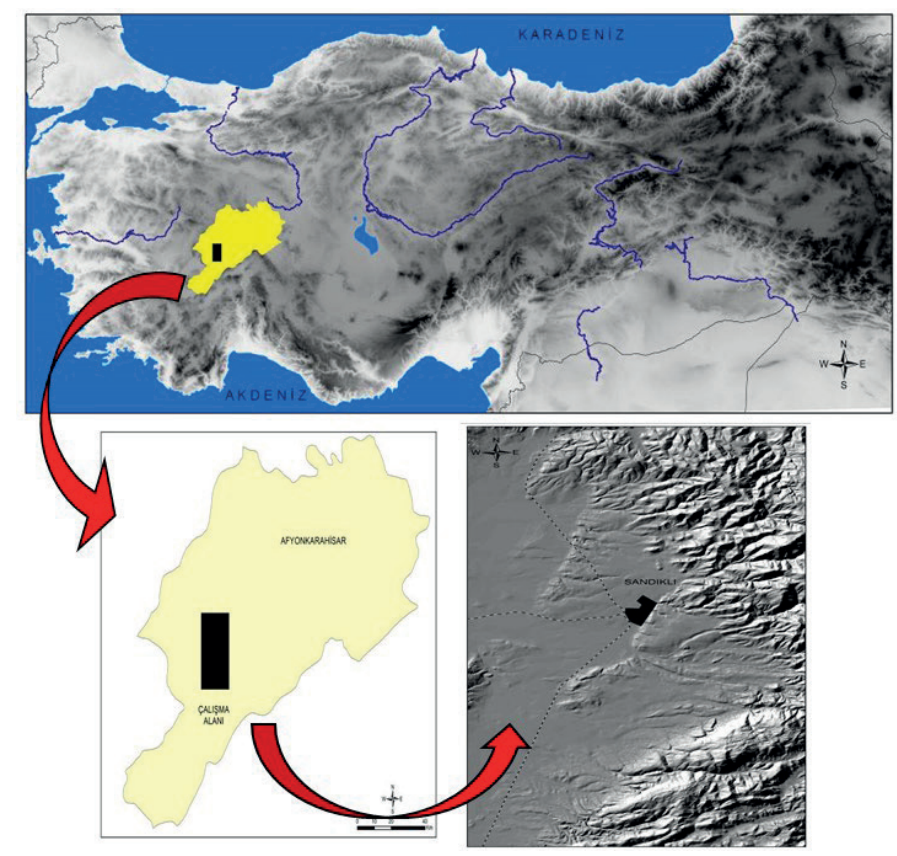

Şekil 1. Çalışma alanı lokasyon haritası

Figure 1. Location map of the study area
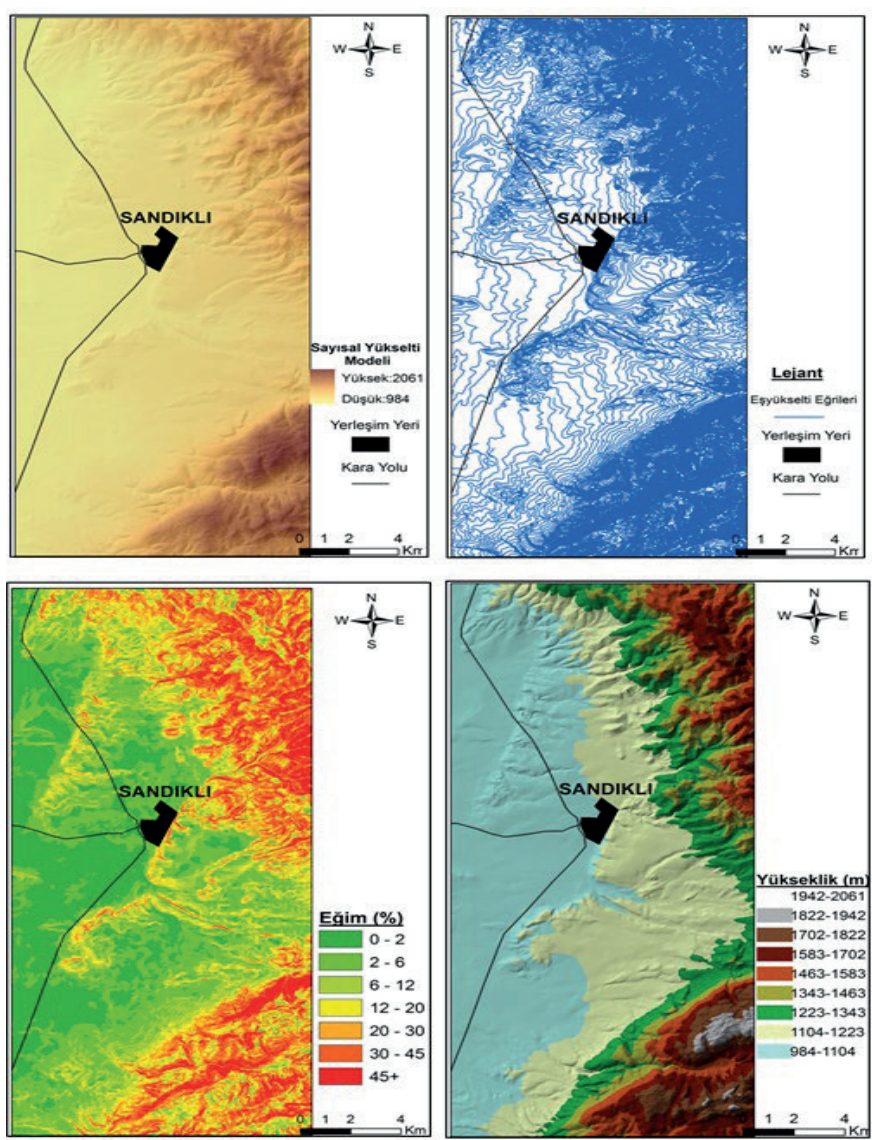

Şekil 2. Çalışma alanına ait sayısal yükselti modeli, eş yükselti, eğim ve yükseklik haritaları Figure 2. Digital elevation model, contour, slope and elevation maps of the study area 
Alanın temelinde Paleozoyik yaşlı çeşitli şist ve metakuvarsitlerden meydana gelen metamorfik kayaçlar bulunur. Temelde yer alan bu metamorfik kayaçların üzerinde, Mesozoyik dönemde çakıltaşı, kumtaş1, silttaş1 gibi kırıntılı ve dolomitik kireçtaşı, kireçtaşı gibi kimyasal sedimanter kayaçlar uyumsuz olarak yer alırlar. Alttaki bu iki ana kayaç gruplarının üzerinde ise; Neojen döneminde bölgede aktif olan bir volkanizmaya bağlı olarak meydana gelen piroklastiklerden ve lavlardan oluşan volkanik kayaçlar bulunur. Bölgede en son olarak kötü çimentolanmış çakıltaşı, kumtaşı, silttaşı gibi kırıntılı litolojilerden oluşan PliyoKuvaterner yaşlı kayaçlar yer alırlar (Anonim, 2011) (Şekil 3).

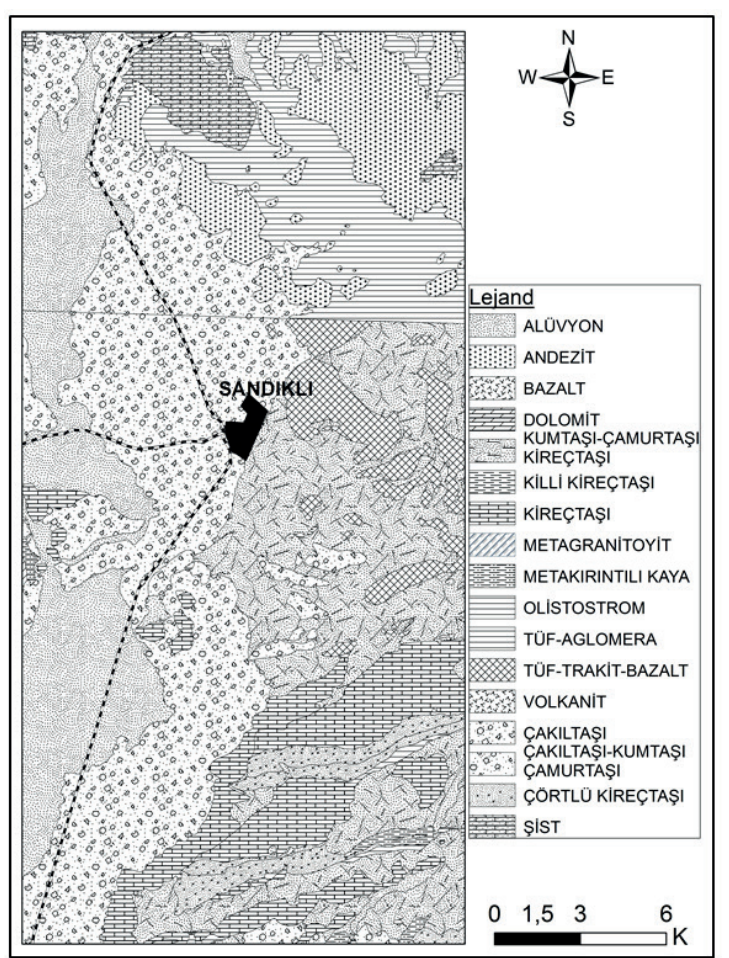

Şekil 3. Çalışma alanı ve çevresinin jeoloji haritası Figure 3. Geological map of the study area and its surroundings

Çalışma alanına ait Afyonkarahisar (Şuhut) Meteoroloji İstasyonu uzun yıllar (1990-2020) iklim verilerine göre; yıllık ortalama sıcaklık 10.8 ${ }^{\circ} \mathrm{C}$, toplam yıllık yağış ortalaması $362.40 \mathrm{~mm}$, yıllık buharlaşma 663.08 mm' dir. Bölgeye en fazla yağış Aralık ayında $(43.9 \mathrm{~mm})$ ve en az yağış ise Eylül ayında $(11.7 \mathrm{~mm})$ düşmektedir. Çalışma alanında kışları soğuk, yazları sıcak ve uzun bir iç Anadolu step iklimi egemendir (Erinç, 1969). Ayrıca, Newhall Simülasyon Modeline göre (Van Wambeke, 2000), toprakların sicaklık rejimi "Mesic", toprak nem rejimi ise "Xeric" altgrup düzeyde ise "Dry Xeric" olarak belirlenmiştir.

\subsection{Yöntem}

Toprak örnekleri magmatik (tüf), sedimanter (çakıltaş1-kiltaşı) ve metamorfik (kuvarsit) kayaçları üzerinde üç adet yerinde oluşmuş toprak profillerine ait horizon bazlı olarak yedi örneklem yapılmıştır.

Mineralojik analizler ve ince kesit: Toprak örneklerinde $2 \mathrm{~mm}$ elekten geçirilmiş kısımlar yaklaşık $38 \mu \mathrm{m}$ (Anonymous, 1993) boyuta kadar agat/tungsten havanda öğütülmüş ve topraklardaki primer minerallerin oransal dağılımı X-ray difraktometre ile belirlenmiștir (Jackson, 1979). Aynı şekilde, kayaç örnekleri de çeneli kırıcıda küçük parçalara ayrılarak, öğütücüde yukarıda belirtilen boyutlara indirgenerek ham olarak toprak örneklerinde olduğu gibi X-ray difraktogramları çekilmiştir. $\mathrm{Bu}$ şekilde yapılan çekimlerde, primer mineraller belirlenmiştir $\left(2 \theta=2-70^{\circ}\right.$ aralığında $)$. Öğütülen örneklerde ayrıca kil mineral tip belirleme amacıyla bazı işlemlerden geçirilmiştir. İlk aşama yıkama işlemi olup; sırasıyla dekantasyon, kirecin uzaklaştırılması, santrifüjleme ve sedimantasyon işlemleridir. Elde edilen kil fraksiyonları, $1 \mathrm{~N} \mathrm{MgCl}$ ve $\mathrm{KCl}$ ile ayrı ayrı doyurulmuş, yıkanmış ve preparatları hazırlanmıştır. Hazırlanan preparatlarda; potasyum $(\mathrm{K})$ ile doyurulan kısımda normal kuru (hava kuru) ve K $550{ }^{\circ} \mathrm{C}$ 'de, magnezyum $(\mathrm{Mg})$ ile doyurulmuş kısımlarda ise normal kuru (hava kuru) ve $\mathrm{Mg} 16$ saat $60{ }^{\circ} \mathrm{C}$ ' de etilen glikol buharında desikatörde bekletme işlemleri gerçekleştirilmiştir. Elde edilen preparatlarda XRD cihazında $\left(2 \theta=2-70^{\circ}\right.$ aralığında $)$ çekimler gerçekleştirilmiştir. Kayaç örneklerinin ince kesitleri yapılarak, kayacı oluşturan mineraller ve kayaçların dokuları mikroskop altına tanımlamaları ve ince kesit fotoğrafları çekilmiştir.

Topraklarin fiziksel ve kimyasal analizleri: $\mathrm{Bu}$ amaçla 2 mm'lik ve $0.5 \mathrm{~mm}$ 'lik elekten geçirilmiş toprak örnekleri kullanılmıştır. Tane büyüklük dağılımı hidrometre yöntemi ile (Bouyoucos, 1951); hacim ağırlığı (HA), $100 \mathrm{~cm}^{3}$ lük metal silindirler içine alınan bozulmamıș örneklerin 105 ${ }^{\circ} \mathrm{C}$ 'de kurutularak silindir hacmine bölünmesi ile (Blake ve Hartge, 1986); toprakların rengi, kuru ve nemli haldeki renkleri Munsell renk skalası kullanılarak (Anonymous, 1993) belirlenmiştir. Topraklara ait toprak reaksiyonu $(\mathrm{pH})$ ve elektriksel iletkenlik (EC), saturasyon çamurunda (Anonymous, 1996); kireç içerikleri, Scheibler kalsimetresi ile volumetrik metotla (Hizalan ve Ünal, 1966); organik madde (OM), modifiye edilmiş Walkley-Black yöntemine göre (Jackson, 1958); katyon değişim kapasitesi (KDK) ve değişebilir katyonlar [magnezyum $\left(\mathrm{Mg}^{++}\right)$, kalsiyum $\left(\mathrm{Ca}^{++}\right)$, sodyum $\left(\mathrm{Na}^{+}\right)$ve potasyum $\left.\left(\mathrm{K}^{+}\right)\right]$, $1 \mathrm{~N} \mathrm{NH} \mathrm{N}_{4} \mathrm{OAc}(\mathrm{pH}=7.0)$ yöntemine göre (Anonymous, 1996) belirlenmiştir. 
Toprakların ayrışma indisleri [CIA (Chemical Index of Alteration)-Kimyasal Alterasyon İndeksi; CIW (Chemical Index of Weathering)-Kimyasal Ayrışma İndeksi; $\mathrm{Baz} / \mathrm{R}_{2} \mathrm{O}_{3}$ oran1], Blakemore (1983) tarafından bildirilen esaslara göre belirlenmiştir.

\section{Bulgular ve Tartışma}

\subsection{Toprakların morfolojik ve fiziko-kimyasal özellikleri}

Magmatik (tüf), sedimanter (çakıltaş1-kiltaşı) ve metamorfik (kuvarsit) kayaçlar üzerinde oluşmuş topraklara ait morfolojik ve fiziko-kimyasal özellikler Tablo 1 ve 2'de verilmiştir. Her üç toprak profili, pedolojik bir gelişime sahip yüzey altı tanı horizonu içermemeleri nedeniyle genç topraklar olarak nitelendirilmektedir. Toprak taksonomisi (Anonymous, 2014a) ve FAO (Anonymous, 2014b)'ya göre sirasiyla, Typic Xerorthent ve Leptosol topraklar olarak sınıflandırılmıştır. PI olarak gösterilen topraklar, çakıl taş1-kil taş1 sedimenter ana materyal üzerinde oluşmuş, sığ derinliğe sahip topraklardır. Profilin bulunduğu eğim \% 12- 20 arasında olup, etek arazi üzerinde yer almaktadır. Profil boyunca bünye, kil ağırlıklı olarak belirlenmiştir. KDK değerleri ise 23.22$27.11 \mathrm{cmol} \mathrm{kg}^{-1}$ arasında değişmektedir. Toprak reaksiyonu hafif alkalin olup, $\mathrm{pH}$ değerleri 7.80 ile 8.00 arasında değişmektedir. Profil boyunca kireç, "orta kireçli" ve "kireçli" sınıfında yer almakta ve profildeki kireç içerikleri \% 4.66 ile \% 11.33 arasında değişmektedir. Organik madde içerikleri $\%$ 0.47-1.41 arasında değişmekte ve profilde derinlik arttıkça organik maddede azalma meydana gelmektedir. Bu durum toprakların renk içeriklerine de yansımakta olup; renk yüzeyde koyu kahverengi olan düşük value değerine sahip iken, alt horizonlara doğru açık sarımsı kahverengine dönüşmektedir. Ayrıca topraklarda tuzluluk problemi de yoktur (Tablo 1 ve 2).

Tüf ana materyali üzerinde oluşmuş ve PII olarak belirtilen topraklar, sı ̆ derinliğe sahiptirler. Profilin bulunduğu eğim \% 2-6 arasında olup, tepe düzlüğü üzerinde yar almaktadır. Profil boyunca bünye, sedimanter ana materyal üzerinde oluşmuş topraklarda olduğu gibi ağırlıklı olarak kil belirlenmiştir. Özellikle yüzey topraklarda kil ve organik madde miktarının yüksek olması nedeniyle orta, iri, granüler strüktür oluşmasına neden olmaktadır. Islak iken çok yapışkan, çok plastik,

Tablo 1. Toprak sınıflama (Anonymous, 2014a) ve FAO (Anonymous, 2014b)'ya göre toprakların sınıfları ve morfolojik tanımlamaları

Table 1. Classes and morphological descriptions of soils according to soil classification (Anonymous, 2014a) and FAO (Anonymous, 2014b)

\begin{tabular}{|c|c|c|}
\hline Derinlik $(\mathrm{cm})$ & Horizon & Tanımlama \\
\hline \multicolumn{3}{|c|}{ PI- Sedimanter (Çakıltaş1-kiltaşı) - Typic Xerorthent - Eutric Leptosols } \\
\hline $0-14$ & A & $\begin{array}{l}\text { Koyu kahverengi (10YR3/3, Kuru), koyu sarımsı kahverengi (10YR3/4, Nemli); kil; orta } \\
\text { ve iri, kuvvetli granüler strüktür; çok yapışkan, çok plastik (1slak), hafif sert (kuru); ince } \\
\text { çok saçak kökler; orta köpürme; dalgalı, kesin sınır. }\end{array}$ \\
\hline $14-26$ & $\mathrm{AC}$ & $\begin{array}{l}\text { Açık sarımsı kahverengi (10YR3/3, Kuru), koyu sarımsı kahverengi (10YR3/4, Nemli); } \\
\text { kil; orta ve iri, kuvvetli granüler strüktür; çok çok yapışkan, plastik (1slak), hafif sert } \\
\text { (kuru); ince çok saçak kökler; orta köpürme; dalgalı, kesin sınır. }\end{array}$ \\
\hline $26-48$ & $\mathrm{C}$ & $\begin{array}{l}\text { Açık sarımsı kahverengi (10YR6/4, Kuru), koyu sarımsı kahverengi (10YR4/4, Nemli); } \\
\text { kil; orta ve iri, kuvvetli granüler strüktür; çok çok yapışkan, plastik (1slak), hafif sert } \\
\text { (kuru); kalın az saçak kökler; küçük, bol çakıl parçaları; şiddetli köpürme; dalgalı, kesin } \\
\text { sınır. }\end{array}$ \\
\hline $48+$ & $\mathrm{R}$ & Altere olmuş çakıl taşları \\
\hline \multicolumn{3}{|c|}{ PII- Mağmatik (Tüf) - Typic Xerorthent - Eutric Leptosols } \\
\hline $0-20$ & A & $\begin{array}{l}\text { Koyu kahverengi gri (10YR3/2, Kuru), koyu sarımsı kahverengi (10YR3/4, Nemli); kil; } \\
\text { orta, iri, granüler strüktür; çok yapışkan, çok plastik (1slak), sert (kuru); çok ince saçak } \\
\text { ve az, orta kökler; bol küçük çak1l tanecikleri; çok az köpürme; dalgalı, belirgin sınır. }\end{array}$ \\
\hline $20-60$ & $\mathrm{C}$ & $\begin{array}{l}\text { Çok koyu grimsi kahverengi (10YR3/2, Kuru), çok koyu kahverengi (10YR3/4, Nemli); } \\
\text { kil; masif; çok yapışkan, çok plastik (1slak), sert (kuru); az, orta kökler; çok az köpürme; } \\
\text { bol küçük ve orta çakıl tanecikleri dalgalı, belirgin sınır; koluviyal tüf karışı1ı1 }\end{array}$ \\
\hline $60+$ & $\mathrm{R}$ & Tüf ana materyal \\
\hline \multicolumn{3}{|c|}{ PIII- Metamorfik (Kuvarsit) - Lithic Xereorthent - Lithic Leptosols } \\
\hline $0-19$ & A & $\begin{array}{l}\text { Sarıms1 kahverengi (10YR5/8, Kuru), koyu sarımsı kahverengi (10YR3/4, Nemli); } \\
\text { kumlu kil tın; orta, orta, granüler strüktür; çok yapışkan, çok plastik (1slak), sert (kuru); } \\
\text { az, ince saçak kökler; orta köpürme; dalgall, belirgin sınır. }\end{array}$ \\
\hline $19-45$ & $\mathrm{C}$ & $\begin{array}{l}\text { Kırmızı (2.5YR4/6, Kuru), koyu kırmızımsı kahverengi (2.5YR3/4, Nemli); kil tın; masif } \\
\text { strüktür; yapışkan, plastik (1slak), hafif sert (kuru); az, ince saçak kökler; orta köpürme }\end{array}$ \\
\hline $45+$ & $\mathrm{R}$ & Kuvarsit \\
\hline
\end{tabular}


Tablo 2. Toprakların bazı fiziko-kimyasal özellikleri

Table 2. Some physico-chemical properties of soils

\begin{tabular}{|c|c|c|c|c|c|c|c|c|c|c|c|c|c|}
\hline \multirow{2}{*}{ Profil } & \multirow{2}{*}{ Horizon } & \multirow{2}{*}{$\mathrm{pH}$} & \multirow{2}{*}{$\begin{array}{c}\text { EC } \\
\left(\mathrm{dS} \mathrm{m}^{-1}\right)\end{array}$} & \multirow{2}{*}{$\begin{array}{c}\mathrm{CaCO}_{3} \\
(\%)\end{array}$} & \multirow{2}{*}{$\begin{array}{l}\mathrm{OM} \\
(\%)\end{array}$} & \multirow{2}{*}{$\begin{array}{l}\text { Kil } \\
(\%)\end{array}$} & \multirow{2}{*}{$\begin{array}{l}\text { Silt } \\
(\%)\end{array}$} & \multirow{2}{*}{$\begin{array}{l}\text { Kum } \\
(\%)\end{array}$} & $\mathrm{Na}$ & $\mathrm{K}$ & $\mathrm{Ca}$ & $\mathrm{Mg}$ & KDK \\
\hline & & & & & & & & & \multicolumn{5}{|c|}{$\mathrm{cmol}^{(+)} \mathrm{kg}^{-1}$} \\
\hline \multicolumn{14}{|c|}{ Sedimanter (Çakıltaşı-kiltaşı) - Typic Xerorthent - Eutric Leptosols } \\
\hline \multirow{4}{*}{ PI } & A & 7.80 & 0.181 & 11.33 & 1.41 & 44.8 & 29.9 & 25.1 & 0.09 & 0.39 & 40.80 & 0.67 & 23.22 \\
\hline & $\mathrm{AC}$ & 8.00 & 0.142 & 7.25 & 0.69 & 52.2 & 28.3 & 19.3 & 0.13 & 0.43 & 44.48 & 0.70 & 27.11 \\
\hline & $\mathrm{C}$ & 7.82 & 0.140 & 4.66 & 0.47 & 55.4 & 22.3 & 22.1 & 0.15 & 0.37 & 41.98 & 0.69 & 26.73 \\
\hline & $\mathrm{R}$ & - & - & - & - & - & - & - & - & - & - & - & - \\
\hline \multicolumn{14}{|c|}{ Magmatik (Tüf) - Typic Xerorthent - Eutric Leptosols } \\
\hline \multirow{3}{*}{ PII } & A & 7.92 & 0.107 & 5.94 & 1.88 & 40.94 & 21.36 & 37.68 & 0.55 & 0.82 & 43.77 & 4.91 & 31.50 \\
\hline & $\mathrm{C}$ & 7.86 & 0.099 & 4.81 & 1.75 & 42.76 & 20.15 & 37.08 & 0.16 & 1.42 & 41.76 & 3.72 & 28.14 \\
\hline & $\mathrm{R}$ & - & - & - & - & - & - & - & - & - & - & - & - \\
\hline \multicolumn{14}{|c|}{ Metamorfik (Kuvarsit) - Lithic Xereorthent - Lithic Leptosols } \\
\hline \multirow{3}{*}{ PIII } & A & 7.05 & 0.096 & 6.58 & 2.32 & 23.08 & 17.41 & 59.49 & 0.06 & 0.52 & 4.86 & 1.31 & 7.87 \\
\hline & $\mathrm{C}$ & 7.35 & 0.045 & 5.77 & 0.52 & 34.49 & 20.62 & 44.88 & 0.01 & 0.79 & 4.52 & 1.71 & 12.84 \\
\hline & $\mathrm{R}$ & - & - & - & - & - & - & - & - & - & - & - & - \\
\hline
\end{tabular}

kuru iken sert kıvamda olduğu belirlenmiștir. Bu durum toprakların kil içeriklerinin yüksek olmasindan kaynaklanmakta; bu nedenle, bu profilin yüzey epipedonu, mollik epipedon olarak değerlendirilmemiştir. KDK değerleri ise 28.14$31.50 \mathrm{cmol} \mathrm{kg}^{-1}$ arasında değişmektedir. Toprak reaksiyonu orta derece alkali olup; kireç profil boyunca "orta kireçli" düzeyde yer almakta ve $\% 4.81$ ile \% 5.94 arasında ve organik madde içerikleri ise \% 1.75-1.88 arasında değişmektedir (Tablo 1 ve 2).

Toprak taksonomisine göre Lithic Xereorthent olarak sınıflandırılan PIII sembol ile gösterilen topraklar, metamorfik bir kayaç olan kuvarsit ana materyali üzerinde oluşmuş, sı ğ derinliğe sahip topraklardır. Profilin bulunduğu eğim \% $\quad 12-20$ arasında olup, yamaç arazi üzerinde yar almaktadır. Profil boyunca, diğerlerine göre kil içeriği düşük olan bu toprakların; killi tın ve kumlu kil tın tekstürde oldukları belirlenmiştir. $\mathrm{Bu}$ durum, bu toprağın KDK değerlerinde de bir miktar düşmesine neden olarak, KDK değerleri 7.8-12.8 $\mathrm{cmol} \mathrm{kg}^{-1}$ arasında değişim göstermiştir. Ayrıca, toprak reaksiyonu nötr olup; profil boyunca kireç kapsamı "orta kireçli" düzeyde ve organik madde içerikleri ise \% 0.52-2.32 arasında dağılım göstermektedir (Tablo 1 ve 2).

\subsection{Ana materyallerin mineralojik ve petrografik incelemeleri}

Çakıl taşı kayacı, büyük çoğunluğunu kireçtaşı çakılları, seyrek olarak volkanik kayaç, şist ve kuvarsların oluşturduğu hemen hemen yuvarlaklaşmış, polijenik, tanelerin kum matriksle tutturulduğu çakııltaşıdır. Çakıltaşını oluşturan tanelerin yaklaşık \% 90 kadarını kireçtaşı, \% 4-5' ini şist, \% 2-3'ünü ise volkanik kayaç parçaları ve seyrek olarak kuvarsların oluşturduğu belirlenmiştir. Çakıllar spari kalsitlerden oluşan bir çimento ile birbirine bağlanarak çimentolanmıştır.
Kireçtaşı çakılları boyut olarak homojen bir dağılım göstermezler. Oldukça büyük taneler olarak bulunduğu gibi, küçük olarak da bulunurlar (Şekil 4). Mikritik, sparitik ve mikrosparitik doku özelliği gösterirler. Metamorfik çakılları kuvarsit ve şist gibi kayaçların taneleri oluşturur. Volkanik çakıllar ise trakitlerden meydana gelmiştir. Kayacı oluşturan çakıllar genel olarak yarı yuvarlak, uzunelips şeklinde, bazen de köşeli olarak bulunurlar.

Ana kaya, kül bir matriks içinde volkanik kayaç ve mineral parçalarının bulunduğu oldukça boşluklu, yumuşak ve kahve renkli piroklastik (tüf) kayaçtır (Şekil 5). Kayaç parçaları genel olarak trakit, trakiandezit ve bazaltik trakiandezit gibi volkanik kayaçlardan, mineraller ise sanidin, plajioklas, piroksen ve mika gibi kristallerden oluşur. Sanidinler yarı özşekilli ve bazen özşekilli olup, temiz görünüşlüdürler. Plajioklaslar polisentetik ikizli, uzun ve bazen kısa levhamsı olarak görülürler. Öz ve yarı özşekillidirler. Kahverenkli pleokroizma gösteren mikalar, uzun çubuksu ve kısa levhamsı prizmalar şeklindedirler. Bir yönde iyi gelişmiş dilinimleri bulunur. Volkanik kayaç tanelerini oluşturan kristaller sanidin, plajioklas ve piroksen türü minerallerdir. Tüfte bulunan kayaç parçaları kayacın yaklaşık \% 15-20 sini, mineraller ise $\% \quad 25-30$ kadarını oluşturmaktadır.

Kuvarsit mineralojik ve petrografik incelemelerinde, kayaç, taze yüzeyi beyaz-açık gri, ayrışma yüzeyi kahve renkli, sert, ince taneli kuvarsittir. Kayaç kuvars ve seyrek olarak bulunan feldispat (plajioklas) tanelerinden oluşmuştur. Kuvarslar genellikle küçük, seyrek olarak orta tane büyüklüklerinde bulunurlar. Bazen bir araya toplanarak, poli kuvars oluşumları gösterirler (Şekil 6). Feldispatlar (plajioklas) bir araya kümelenmiş ve bazen de birey kristaller olarak bulunurlar. Alterasyondan etkilenmiş olduklarından serizit ve killeşmeler meydana gelmiştir. 

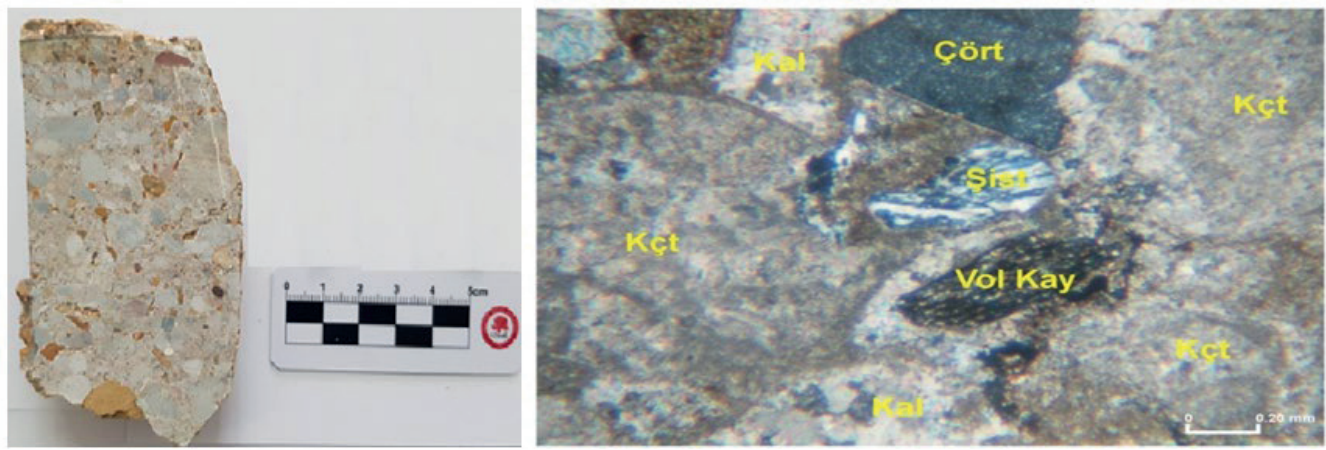

Şekil 4. Tanelerin kum matriksle tutturulduğu çakıltaşı görünümü ve yaklaşık \% 90 kadarını kireçtaşı çakıllarının oluşturduğu çakıltaşının mikroskopik görüntüsü*

*: Kayaçtaki diğer çakıllar çört, şist ve volkanik kayaç tanelerinden oluşur. Bunlar karbonat (kalsit) bir çimento ile tutturulmuşlardır. Çift nikol, Kçt: Kireçtaşı, Vol Kay: Volkanik kayaç, Kal: Kalsit

Figure 4. The appearance of the sandstone, where the grains are attached to the sand matrix, and the microscopic image of the sandstone formed by about $90 \%$ of the limestone pebbles*

*: Other gravels in the rock consist of chortles, schists and grains of volcanic rock. They are attached with a carbonate (calcite) cement. Double nicol, Kçt: Lime stone, Vol Kay: Volcanic rock, Kal: Calcite
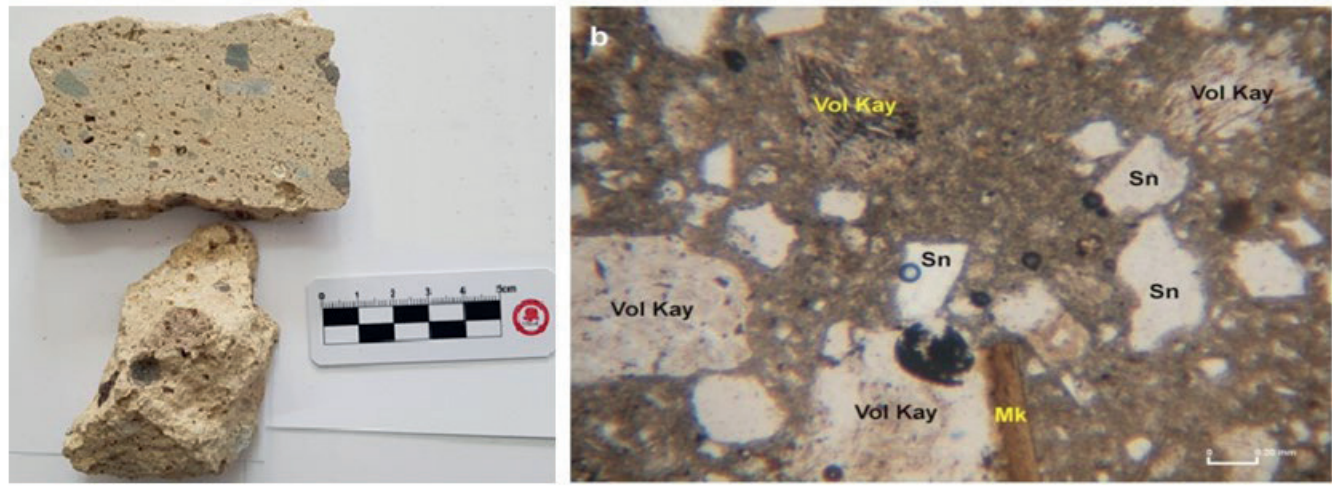

Şekil 5. Volkanik kayaç ve mineral parçalarından oluşan tüf ve piroklastik kayaç olan tüfün mikroskopik görüntüleri"

*: Kül bir matrikste bulunan volkanik kaya parçaları ile sanidin ve mika gibi kristallerinden oluşmuștur. Tek nikol, Vol Kay: Volkanik kayaç, Sn: Sanidin, Mk: Mika

Figure 5. Microscopic images of tuff and pyroclastic rock, which are composed of volcanic rock and mineral fragments ${ }^{*}$

*: Ash is composed of volcanic rock fragments found in a matrix and crystals such as sanidine and mica. Single nicol, Vol Kay: Volkanic rocks, Sn:Sanidine, Mk: Mica
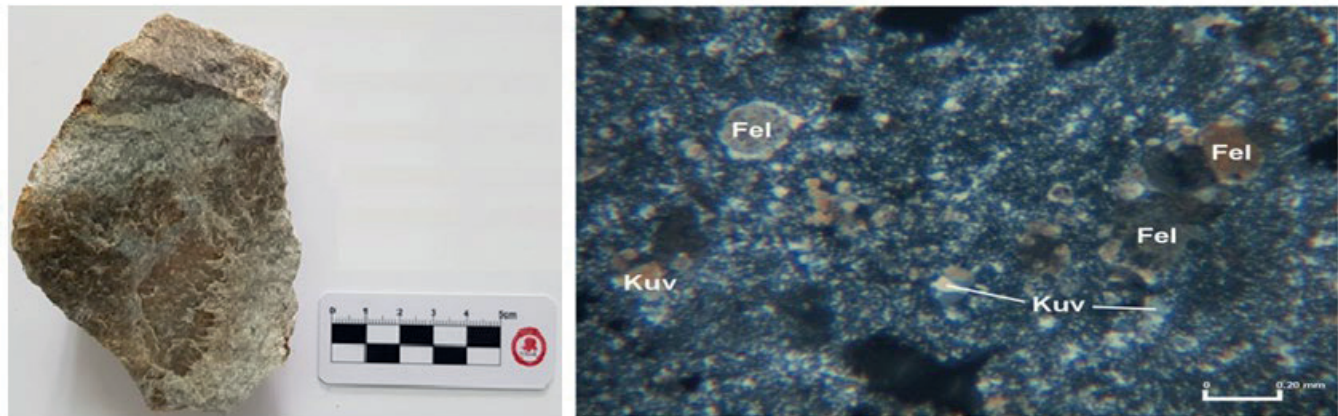

Şekil 6. İnce taneli kuvarsit görünümü*

*: Kayaç kuvars ve seyrek olarak bulunan feldispat (plajioklas) tanelerinden oluşmuştur. Kuvarslar genellikle küçük, seyrek olarak orta tane büyüklüklerinde bulunurlar. Feldispatlar (plajioklas) bir araya kümelenmiş ve bazen de birey kristaller olarak bulunurlar, Kuv: Kuvars, Fel: Feldispat

Figure 6. Fine-grained quartzite appearance*

*: Rock consists of quartz and sparsely found feldspar (plagioclassic) grains. Quartzies are usually small, rarely found in medium grain sizes. Feldspars (plagioclas) are found clustered together and sometimes as deciduous crystals, Kuv: Quartz, Fel: Feldspar 


\subsection{Toprakların primer ve kil mineralleri}

Çalışma alanında açılan PI nolu profilin mineralojik özelliklerini belirlemek için toprak gövdesinde çekilen X-ray difraktomları Şekil 7'de ve bolluk dağılımlarını ise Tablo 3 'te verilmiştir. PI nolu toprak, çakıltaşı (kumtaşı ve kiltaşı) ana materyal üzerinde oluşmuştur. Toprak gövdesinde birincil minerallerin belirlenme çalışmaları $2-70^{\circ}$ (20) aralığında yapılmış, nontronit, muskovit, kalsit, kuvars mineralleri tespit edilmiştir. Ayrıca muskovit, 5.02, $\AA$ minerali sadece A horizonunda bulunmakta; $2.13 \AA$ bulunan muskovit ve kuvars mineralleri $\mathrm{C}$ horizonunda bulunmamaktadır (Şekil 7).

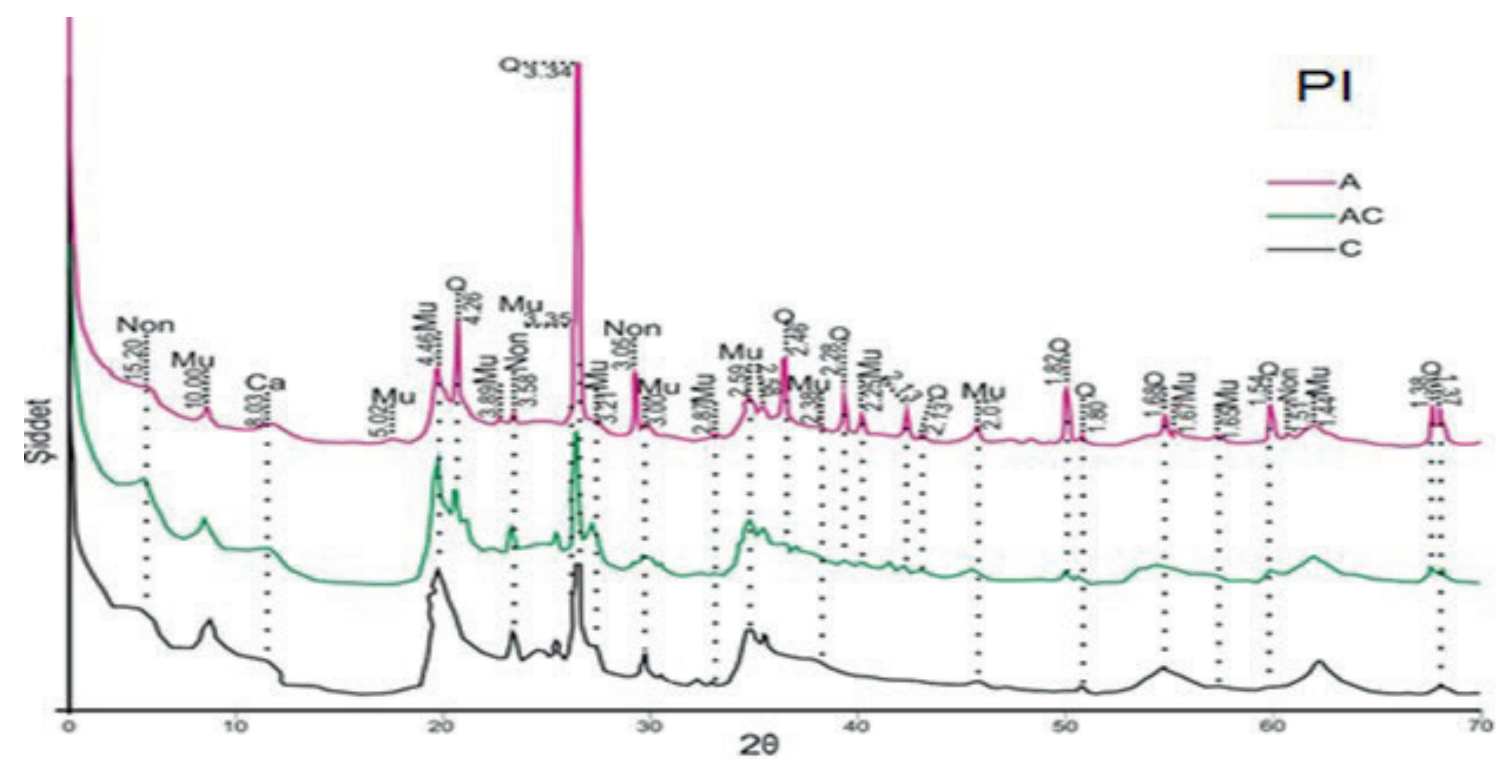

Şekil 7. PI nolu toprak profili primer minerallere ait X-ışını kırınımları

Non: Nontronit, Mu: Muskovit, Ca: Kalsit, Q: Kuvars

Figure 7. X-ray diffraction of primary minerals for soil profile PI

Non: Nontronite, Mu: Muscovite, Ca: Calcite, Q: Quartz

Tablo 3. Çakıltaşı ana materyal üzerinde oluşmuş toprakların primer minerallerin dağılımı

Table 3. Distribution of primary minerals of soils formed on sandstone-claystone material

\begin{tabular}{clllllllllllllll}
\hline \multicolumn{10}{c}{ Sedimanter (Çak1taş1-kiltaş1) - Typic Xerorthent - Eutric Leptosols } \\
\hline Horizon & $\mathrm{a}$ & $\mathrm{b}$ & $\mathrm{c}$ & $\mathrm{d}$ & $\mathrm{e}$ & $\mathrm{f}$ & $\mathrm{g}$ & $\mathrm{h}$ & $\mathrm{i}$ & $\mathrm{j}$ & $\mathrm{k}$ & 1 & $\mathrm{~m}$ & $\mathrm{n}$ \\
\hline $\mathrm{A}$ & + & - & - & ++++ & +++ & - & - & - & - & - & - & - & + & - \\
$\mathrm{AC}$ & + & - & - & +++ & ++++ & - & - & - & - & - & - & - & ++ & - \\
$\mathrm{C}$ & + & - & - & ++ & ++++ & - & - & - & - & - & - & - & ++ & - \\
\hline
\end{tabular}

Bolluk: Çok bol (++++), Fazla (+++), Orta (++), Az (+); Mineraller: a: Kalsit, b: Sanidin, c: Mikroklin, d: Kuvars, e: Muskovit, f: Albit, g: Gismondin, h: Fillipsit, i: Ortoklas, j: Ankerit, k: Şabazit, 1: Anortoklas, m: Nontronit, n: Montmorillonit

Tüf ana materyal üzerinde oluşmuş PII kodlu toprak genç toprak niteliğinde ve Typic Xerorthent olarak sınıflandırılmıștır. Mineralojik özelliklerini belirlemek amacı ile yüzeyden itibaren $\mathrm{A}$ ve $\mathrm{C}$ horizonlarından örnekleme yapılmıştır ve örneklerde çekilen X-ray difraktomları Şekil 8'de verilmiștir. Toprak gövdesinde birincil minerallerin belirlenme çalışmaları 2-70 ${ }^{\circ} \quad(2 \theta)$ aralığında yapılmış, nontronit, alunogen, sanidin, muskovit, albit, anortit ve ortoklas mineralleri tespit edilmiştir. Ayrıca muskovit $7.17 \AA$ ve ortoklas C horizonunda bulunmamıştır (Şekil 8). Yoğunluk sırasına göre ise sanidin, ortoklas, muskovit, nontronit, alunogen, albit, anortit belirlenmiştir (Tablo 4). 


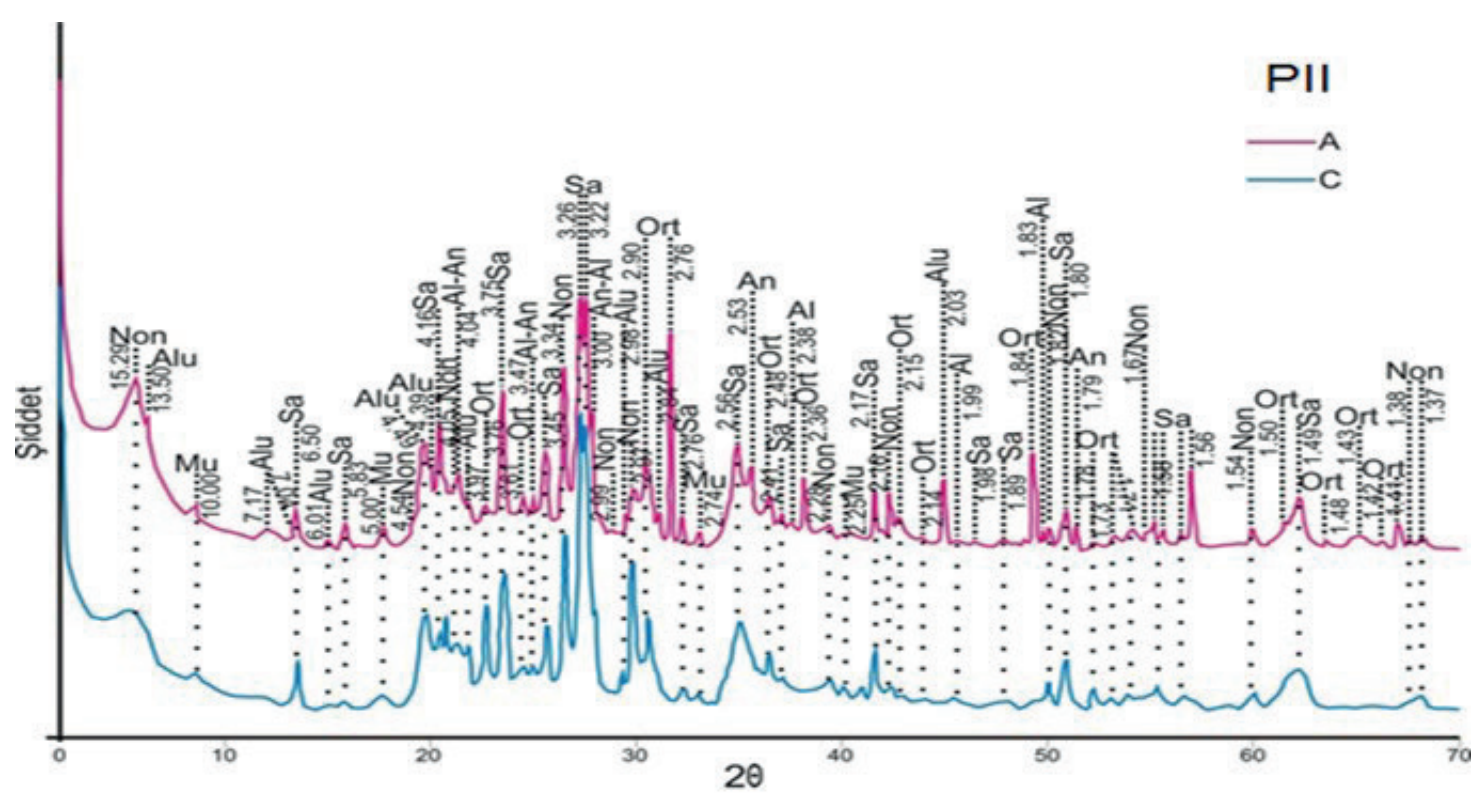

Şekil 8. PII nolu toprak profili primer minerallere ait X-ışını kırınımları Sa: Sanidin, Ort: Ortoklas, Non: Nontronit, Alu: Alunogen, Al: Albit, An: Anortit Figure 8. X-ray diffraction of primary minerals for soil profile PII Sa: Sanidin, Ort: Orthoclase, Non: Nontronite, Alu: Alunogen, Al: Albite, An: Anorthite

Tablo 4. Tüf ana materyal üzerinde oluşmuş toprakların primer mineral dağılımı Table 4. Distribution of primary minerals of soils formed on tuff material

\begin{tabular}{ccccccccccccccccccccccccc}
\hline & \multicolumn{11}{c}{ Magmatik (Tüf) - Typic Xerorthent - Eutric Leptosols } \\
\hline Horizon & $\mathrm{a}$ & $\mathrm{b}$ & $\mathrm{c}$ & $\mathrm{d}$ & $\mathrm{e}$ & $\mathrm{f}$ & $\mathrm{g}$ & $\mathrm{h}$ & $\mathrm{i}$ & $\mathrm{j}$ & $\mathrm{k}$ & $\mathrm{l}$ & $\mathrm{m}$ & $\mathrm{n}$ & $\mathrm{o}$ & $\mathrm{p}$ & $\mathrm{r}$ & $\mathrm{s}$ & $\mathrm{t}$ & $\mathrm{u}$ \\
$\mathrm{A}$ & - & ++++ & - & - & ++ & + & - & - & +++ & - & + & + & - & - & - & - & + & - & - & - \\
$\mathrm{C}$ & - & ++++ & - & - & + & + & - & - & +++ & - & + & + & - & - & - & - & + & - & - & - \\
\hline
\end{tabular}

Bolluk: Çok bol (++++), Fazla (+++), Orta (++), Az (+); Mineraller: a: Kalsit, b: Sanidin, c: Mikroklin, d: Kuvars, e: Muskovit, f: Albit, g: Gismondin, h: Fillipsit, i: Ortoklas, j: Anortoklas, k: Alunogen, 1: Anortit, m: Antigorit, n: Diyopsit, o: Labradorit, p: Kristobalit, r: Nontronit, s: Montmorillonit, t: Rankinit, u: Viksit

Derinlikle birlikte Plajioklas grubunun sodyumca zengin bir üyesi olan albit mineralinin şiddetinde artış gözlenmiştir. Pegmatitlerde, sodyumca zengin lavlarda, metamorfik kayaçlarda ve bazı kırıntılı kayaçlar da bulunmaktadır. Alunogen $\left[\mathrm{Al}_{2}\left(\mathrm{SO}_{4}\right)_{3}\right.$ x $\left.17 \mathrm{H}_{2} \mathrm{O}\right]$ hidrate alüminyum (Al) mineralidir. Bu mineral, kurak ve yarı kurak iklim koşullarında şeyl gibi Al içeren kayaçların sülfitler ile reaksiyonu sonucu oluşan ve yapısında sülfata dönüşen bir mineraldir. Volkanik etkinlik devreleri bittikten sonra sicak gaz, buhar ve su püskürtmeye devam eder. Basınç ve sıcaklığın düşmesiyle ilk ürün fümeroller $\left(800-200 \quad{ }^{\circ} \mathrm{C}\right)$ gazların yoğunlaşması alunogen gibi mineraller de oluşmaktadır (Şimşek, 2000). Tüf ana materyalin özelliklerini doğrudan yansıtan çekimler kayaç mineralojik özelliklerine paralel sonuçlar vermiştir. Nitekim mineralojik ve petrografik incelmelerde kül bir matriks içinde volkanik kayaç ve mineral parçalarının bulunduğu oldukça boşluklu, yumuşak ve kahve renkli piroklastik (tüf) kayaç özelliği sunan ana materyaldir (Şekil 8).

Çalışma alanında açılan PIII nolu profilin mineralojik özellikleri Şekil 9' da ve bolluk dağılımı ise Tablo 5'te verilmiştir. Lithic Xereorthent olarak sinıflandirılan PIII nolu toprak profili A-C-R horizon dizilimine sahip, kuvarsit ana materyal üzerinde oluşmuştur. Mineralojik özelliklerini belirlemek amacı ile yüzeyden itibaren A ve C horizonlarından örnekleme yapılmıştır. Toprak gövdesinde muskovit ve kuvars mineralleri tespit edilmiştir (Şekil 9).

Minerallerin yoğunluk sırasına göre ise PIII profilinde kuvars ve az oranda muskovit belirlenmiştir. Ayrıca, mineralojik ve petrografik incelemelerde ana kayanın kuvarsit olduğu tespit edilmiştir. PIII profiline yer alan C horizonundaki muskovit mineraline ait pik şiddetlerinde çok az da olsa artma görülmüş ama baskın mineral kuvars olarak belirlenmiştir (Tablo 5).

Toprakların sekonder mineralleri olarak bilinen kil çeşitlerine ait dağılım ise PI olarak kodlanan ve çakıltaş1-kil taşı ana materyal üzerinde oluşan topraklarda kil fraksiyonu X-ray difraktomları Şekil 10 'da verilmiştir. $\mathrm{Mg}$ ile doyurulan (Mgad) örneklerinde 14.38-15.01 $\AA$ aralığında zayıf kristalize olmuş ve plato şeklinde görülen doruklar 


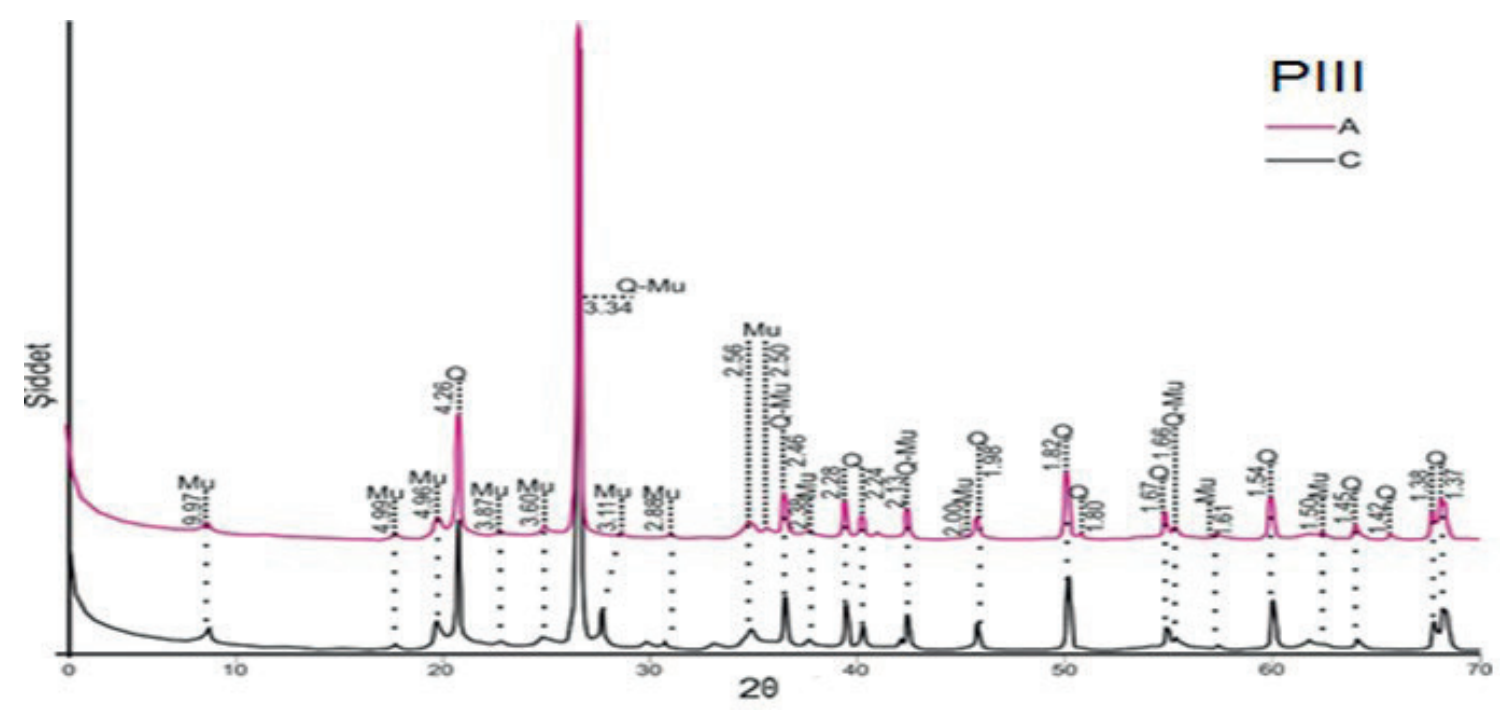

Şekil 9. PIII nolu toprak profili primer minerallere ait X-ışını kırınımları

Q: Kuvars, Mu: Muskovit

Figure 9. X-ray diffraction of primary minerals for soil profile PIII

Q: Quartz, Mu: Muscovite

Tablo 5. Kuvarsit ana materyal üzerinde olușmuş primer minerallerin dağılımı

Table 5. Distribution of primary minerals of soils formed on quartzite material

\begin{tabular}{cccccccccccccccc}
\hline \multicolumn{11}{c}{ Kuvarsit - Lithic Xereorthent - Eutric Leptosols } \\
\hline Horizon & $\mathrm{a}$ & $\mathrm{b}$ & $\mathrm{c}$ & $\mathrm{d}$ & $\mathrm{e}$ & $\mathrm{f}$ & $\mathrm{g}$ & $\mathrm{h}$ & $\mathrm{i}$ & $\mathrm{j}$ & $\mathrm{k}$ & 1 & $\mathrm{~m}$ & $\mathrm{n}$ & $\mathrm{o}$ \\
$\mathrm{A}$ & - & - & ++++ & - & - & - & - & - & - & - & - & - & - & - & ++ \\
$\mathrm{C}$ & - & - & ++++ & - & - & - & - & - & - & - & - & - & - & - & ++ \\
\hline
\end{tabular}

Bolluk: Çok bol (++++), Fazla (+++), Orta (++), Az (+); Mineraller: a: Sanidin, b: Mikroklin, c: Kuvars, d: Albit, e: Ortoklas, f: Anortoklas, g: Anortit, h: Kristobalit, i: Nontronit, j: Glokonit, k: Fillipsit, 1: Flogopit, m: Antigorit, n: Dolomit, o: Muskovit
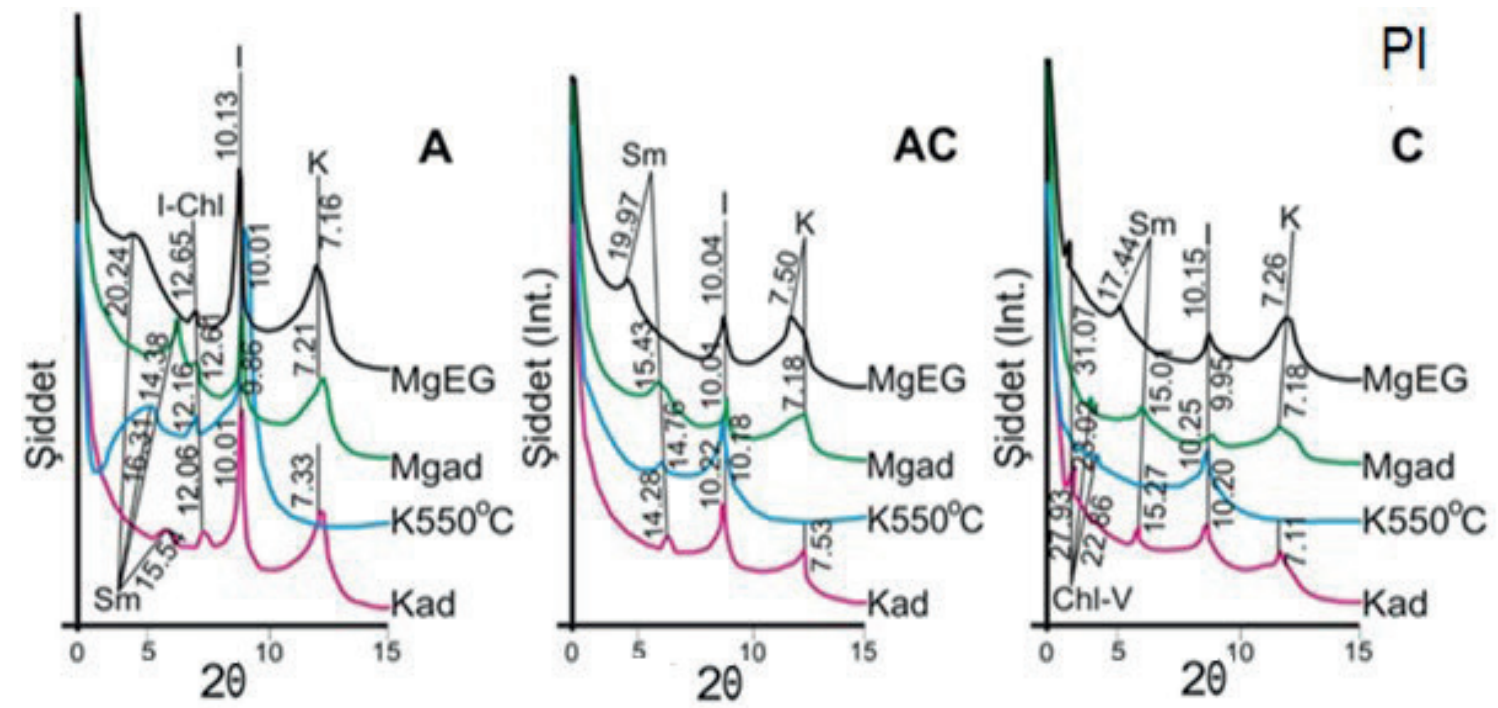

Şekil 10. PI nolu toprak profili kil fraksiyonu X-ışını diyagramı I: illit, K: Kaolinit, Sm: Smektit, F: Feldispat

Figure 10. Clay fraction X-ray diagram of soil profile PI

I: Illite, K: Kaolinite, Sm: Smectite, F: Feldspar 
Mg-EG (Mg-Etilen Glikol) uygulamasında 17.4420.24 Å’a açılmıştır. Potasyum ile doyurmada (Kad) ise bu pikler 12.87-14.24 $\AA$ aralığına kapanmıştır. Doruklar smektit mineralinin varlığına işaret etmektedir. Magnezyum ile doyurmalarda bu doruklar plato şeklindedir ve kristalize olmamıştır. Tüm uygulamalarda 9.86-10.25 $\AA$ aralığında görülen doruklar iyi kristalin illite aittir. Magnezyum, magnezyum-etilen glikol ve potasyum ile doyurulan örnekler, 7.18-7.53 $\AA$ aralığında görülen doruklar $550{ }^{\circ} \mathrm{C}$ 'de $\left(\mathrm{K} 550^{\circ} \mathrm{C}\right)$ 1sitılinca kaybolmuştur. $\mathrm{Bu}$ durum söz konusu dorukların kaolinite ait olduğunu göstermektedir. A horizonunda tüm uygulamalarda 12.06-12.65 $\AA$ aralığında görülen çok zayıf kristalize olmuş doruklar İllit-klorit ara tabakalı kil mineralinin olduğunu göstermiştir. $\mathrm{C}$ horizonunda $\mathrm{K}$ ile doyurulan örnekte $27.93 \AA$ \&örülen doruk, Mg-EG doyurma işlemi sonucu $31.07 \AA$ kayma göstermiştir. K $550{ }^{\circ} \mathrm{C}$ ve Mgad doyurmaları sonucu sırası ile $22.86 \AA$ ve $23.22 \AA$ 'a kapanmış; $\mathrm{K}$ $550{ }^{\circ} \mathrm{C}$ uygulanan örnek şiddetinde de, hafif de olsa bir artma görülmüştür. Profilde horizonlar arasında killerin dağılımında anlamlı farklar gözlenmemiştir. Bolluk sırasına göre ise killerin dağılımı illit, kaolinit ve smektit şeklinde olmuştur. Profilde derinlik bazında sıralama değişmese de smektit miktarında artma gözlenmiştir. A horizonunda kristalize olmamıș illit-klorit ara tabakalı kil minerali derinlikle birlikte kaybolurken, C horizonunda kristalize olmamış klorit-vermiküllit ara tabakalı killer tespit edilmiştir (Şekil 10).

Çalışma alanı PII nolu toprak profilinde mineralojik özelliklerini belirlemek için kil fraksiyonu X-ray difraktomları Şekil 11'de verilmiştir. Profilde $\mathrm{Mg}$ ile doyurulan (Mgad) örneklerde 14.52 ve $15.01 \AA ̊$ 'da kristalize olmuş doruklar MgEG uygulamasinda 19.53 ve 19.61 A’a açılmıştır. Potasyum ile doyurmada (Kad) bu pikler 12.65 ve $13.34 \AA \AA$ 'a kapanmıştır. Doruklar kristalize olmuş smektit mineralinin varlığına işaret etmektedir. Tüm uygulamalarda 9.86-10.44 $\AA$ aralığında görülen doruklar kristalize illite aittir. Mgad, MgEG ve Kad ile doyurulan örnekler 7.18 $7.25 \AA$ aralığında görülen doruklar $550{ }^{\circ} \mathrm{C}$ 'de $\left(\mathrm{K} 550{ }^{\circ} \mathrm{C}\right)$ 1sitılinca kaybolmuştur. Bu durum söz konusu dorukların kaolinite ait olduğunu göstermektedir. Tüm uygulamalarda 6.38-6.51 aralığında görülen doruklar feldispat mineralidir. Toprakların yaygın minerali olan feldispatların tali dorukları kum, silt ve kil fraksiyonunda bulunabilir (Sparks, 2003). Bolluk sirasina göre ise killerin dağılımı smektit, illit ve kaolinit şeklinde olmuştur.

Çalışma alanı PIII nolu ve kuvarsit ana kayası üzerinde oluşmuş toprak profilinde mineralojik özelliklerini belirlemek için kil fraksiyonu X-ray difraktomları Şekil 12'de verilmiştir. Tüm uygulamalarda 9.71-10.71 $\AA$ aralı̆̆ında görülen doruklar kristalize olmuş illite aittir. Mgad, MgEG ve $\mathrm{Kad}$ ile doyurulan örnekler 7.03-7.23 $\AA$ aralığında görülen doruklar $550{ }^{\circ} \mathrm{C}$ 'de $\left(\mathrm{K} 550{ }^{\circ} \mathrm{C}\right)$ 1sıtılınca kaybolmuştur (Şekil 12). Bu durum söz konusu dorukların kristalize kaolinite ait olduğunu göstermektedir. Profilin $\mathrm{C}$ horizonunda $\mathrm{Mg}$ ile doyurma ve MgEG uygulamalarında sırası ile 14.06 $\AA$ ve 13.84 Å'daki pikler kristalize olmamış vermiküllit mineraline aittir. Bolluk sırasına göre dizilim ise A horizonunda illit ve kaolinit, C horizonunda ise illit, kaolinit ve vermiküllit şeklindedir. C horizonunda illit ve kaolinit pik şiddetlerinde artma belirgindir (Tablo 5).
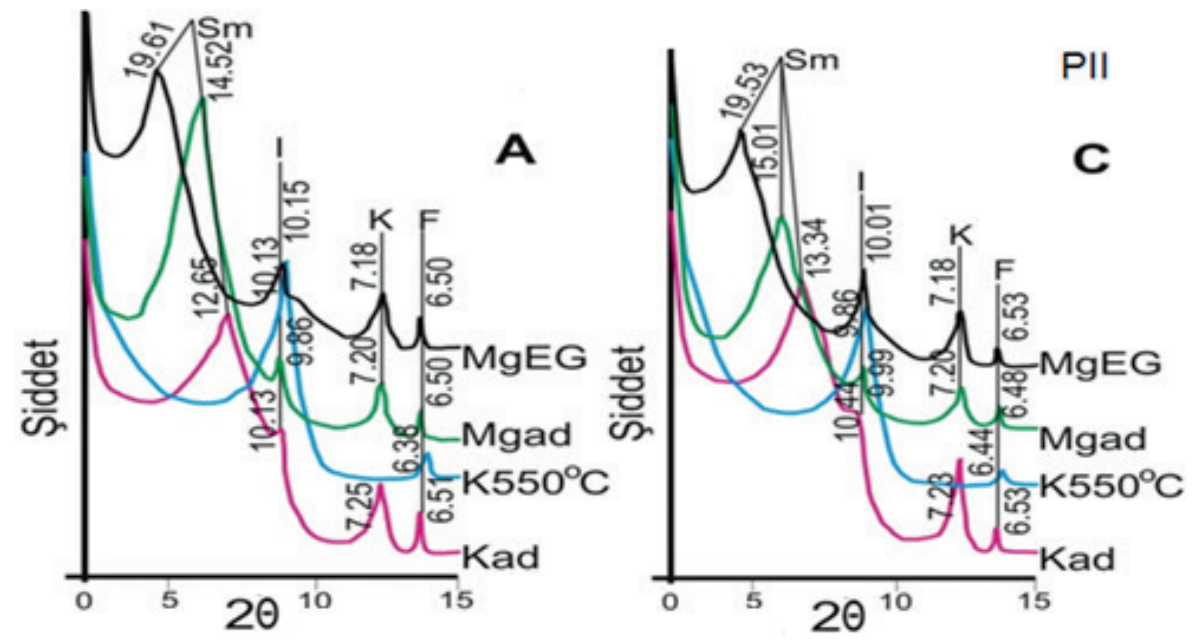

Şekil 11. PII nolu toprak profili kil fraksiyonu X-ışını kırınımları I: İllit, K: Kaolinit, Sm: Smektit, F: Feldispat

Figure 11. Clay fraction X-ray diagram of soil profile PII I: Illite, K: Kaolinite, Sm: Smectite, F: Feldspar 


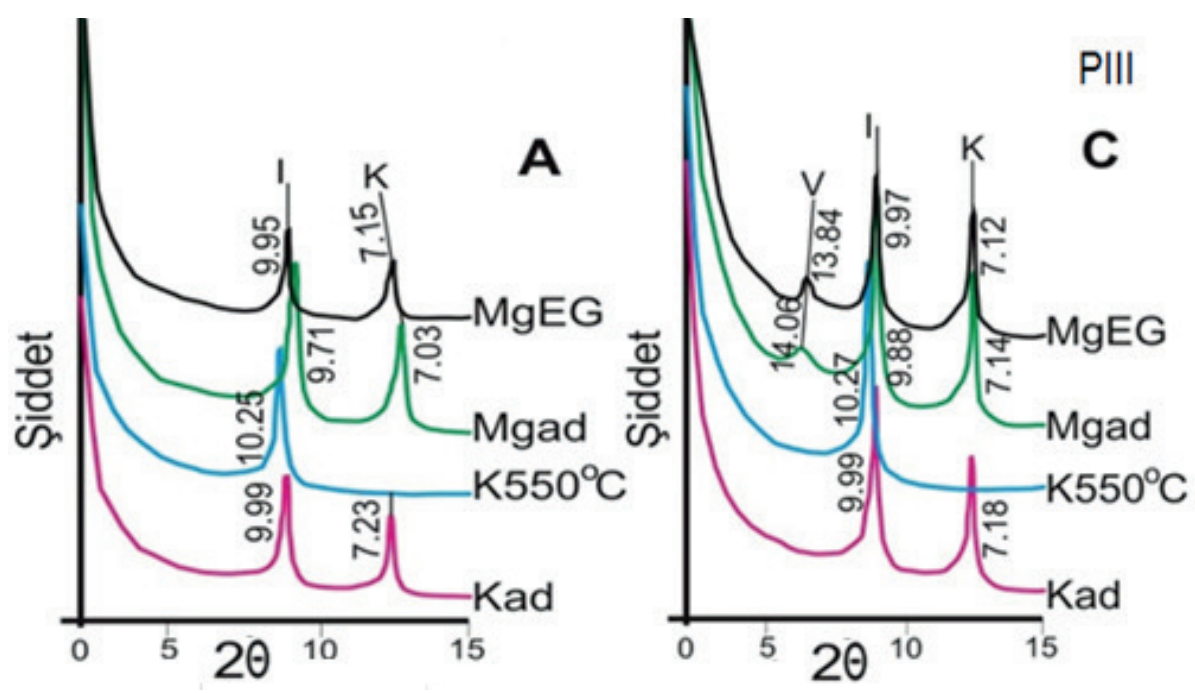

Şekil 12. PIII nolu toprak profili kil fraksiyonu X-ışını kırınımları I: İlit, K: Kaolinit, V: Vermiküllit

Figure 12. Clay fraction X-ray diagram of soil profile PIII I: Illite, K: Kaolinite, V: Vermiculite

\subsection{Toprakların ayrıșma oranları}

Topraklardaki parçalanma ve ayrışma derecelerinin tanımlanmasında birçok farklı indeks kullanılmaktadır (Nesbit ve Young, 1982, Harnois, 1988). İndekslerin temel esası, bazik katyonlar ile Al ve silisyum gibi katyonlar arasındaki değişim oranlarının sayısallaştırılmasıdır. Çalışma alanına ait farklı ana materyallerde oluşan toprakların indisler ve indislere ait değerler Tablo 6'da verilmiştir. Kimyasal ayrışmadan dolayı bazik katyonların minerallerden uzaklaşmasına dayanan CIA indisi, topraktaki primer ve sekonder minerallerin oranlarını yansıtmaktadır. İleri düzeyde parçalanma ayrışma ile beraber bu oran çoğalarak 100'e doğru yaklaşmaktadır. Nesbit ve Young (1982) CIA değerlerini; yüzde olarak çok az ayrışmış (\% 50-60), az ayrışmış (\% 60-80), ileri derecede ayrışmış (\% $80-90)$ ve aşırı ayrışmış (\% 90-100) olarak sınıflandırmışlardır. Arazide belirlenen farklı ana materyal üzerinde oluşan topraklara ait profillerin CIA değerlerini Nesbitt ve
Young (1982) tarafindan önerilen bu sinıflamaya göre PI nolu (C1 horizonu hariç) ve PII nolu toprak profilleri "çok az ayrışmış" (\% 50-60) sınıfina girmiştir. PIII nolu profil ise az ayrışmış (\% 60-80) olduğunu göstermektedir.

CIW değerleri ise parçalanma ayrışmaya uğramamış kayaçlarda \% 50, artan ayrışmaya derecesine bağl1 olarak bu indis ise \% 100'e kadar ulaşmaktadır. Topraklarda CIW değerleri CIA'daki bir trend göstermekte olup, PII nolu toprak profili "çok az ayrışmış" (\% 50-60) sınıfına girmiştir, PI (C horizonu hariç) "az ayrışmış" (\% 60-80) ve PIII nolu profil diğerlerine göre fazla derecede ayrışmış olduğu belirlenmiştir (Tablo 6). Tunçay ve ark. (2019), Türkiye'nin yarı kurak bir bölgesinde eski göl çökelleri üzerinde gelişen topraklara uygulanan kimyasal ayrışma indekslerini belirlemişlerdir. Araştırmacılar; Xeric Haplocambid ve Xeric Haplocalcic olarak sinıflandırdıkları 4 adet toprak profilinde, CIA değerlerinin 6.60-66.88 arasında, CIW değerlerinin ise 6.68 ve 78.37 (çok az ve az

Tablo 6. Toprakların ayrışma indislerine ait değerler Table 6. Values of weathering indices of soils

\begin{tabular}{|c|c|c|c|c|}
\hline Profil no & Horizon & CIA & CIW & $\mathrm{Baz} / \mathrm{R}_{2} \mathrm{O}_{3}$ \\
\hline \multirow{4}{*}{ PI } & \multicolumn{4}{|c|}{ Çakı1 taşı-kiltaşı ana materyal üzerinde oluşmuş topraklar (Typic Xerorthent) } \\
\hline & A & 55.75 & 63.01 & 0.43 \\
\hline & $\mathrm{AC}$ & 60.55 & 71.28 & 0.28 \\
\hline & $\mathrm{C}$ & 35.84 & 40.86 & 1.33 \\
\hline \multirow{3}{*}{ PII } & \multicolumn{4}{|c|}{ Tüf ana materyal üzerinde oluşmuş topraklar (Typic Xerorthent) } \\
\hline & A & 52.36 & 61.08 & 0.97 \\
\hline & $\mathrm{C}$ & 53.00 & 61.00 & 0.98 \\
\hline \multirow{3}{*}{ PIII } & \multicolumn{4}{|c|}{ uvarsit ana materyal üzerinde oluşmuş topraklar (Lithic Xereorthent) } \\
\hline & A & 72.94 & 86.72 & 0.42 \\
\hline & $\mathrm{C}$ & 81.34 & 95.00 & 0.30 \\
\hline
\end{tabular}


ayrışan) arasında değiştiğini belirlemişlerdir. Çalışmalarına göre, ayrışma sürecinin Xeric Haplocambids toprakların Xeric Haplocalcid topraklara göre daha yoğun olduğunu rapor etmişlerdir.

$\mathrm{Baz} / \mathrm{R}_{2} \mathrm{O}_{3}$ oran1 topraklarda 0 ile 10 arasında değişiklik göstermektedir (Şenol ve ark, 2014). Ana kaya da ise yüksek değerlere yaklaşır. PI nolu toprak profilin AC horizonuna doğru azalma ve tekrar artma, PII nolu profillerde artma, ve PIII nolu profillerde derine indikçe azalma olduğu görülmüştür. Farklı ana materyaller üzerinde gelişim gösteren toprakların her üçü de genç olmalarına karşın, kuvarsit ana materyal üzerinde oluşmuş PIII nolu profilin ayrışma indisleri yönünden bir miktarda olsa diğerlerine göre ayrışması daha fazla olduğu görülmektedir (Tablo $6)$.

\section{Sonuçlar}

Afyonkarahisar ili Sandıklı-Şuhut ilçeleri arasındaki aynı iklim koşullarında farklı ana materyal üzerinde oluşmuş toprakların belirlenmesine yönelik olarak, belirlenen alandan anakaya/anamateryal, farklılıkları göz önünde bulundurularak; kuvarsit ana materyal üzerinde oluşmuş topraklar (Lithic Xereorthent), Tüf ana materyal üzerinde oluşmuş topraklar (Typic Xerorthent), Çakıl taşı-kil taşı ana materyal üzerinde oluşmuş topraklar (Typic Xerorthent), olmak üzere toplam üç adet toprak profili incelenmiştir. Çalışma alanı topraklarının toprak taksonomisine göre sinıflandırılması, toprakların pedogenetik özellikleri ile üst tanı horizonları (epipedon) ve bunların altında bulunan yüzey altı tanı horizonları ve özelliklerine göre yapılmıştır. Toprakların oluşum süreçleri henüz bir yüzey altı tanı tanı horizonları saptanmamış olmaları nedeniyle genç topraklar olarak nitelendirilen Entisol ordosuna dahil edilmiştirler. Pirimer ve sekonder (kil) mineralleri olarak PI ve PIII nolu topraklarda kuvars ve kil minerali olarak illit ve kaolinit yayın olarak belirlenmiş iken PII nolu profilde sanidin-ortokla primer mineral ve çakıltaşıkiltaşı karışımı nedeniyle illit ve özellikle smektit kil mineralleri belirlenmiştir. Toprakların ayrışma oranları yönünden karşılaştırıldığında, farklı ana materyaller üzerinde yer alan her üç toprakta oluşumlarının başlangıç aşamasında olup, topraklar fiziko-kimyasal, jeokimyasal ve minerolojik özellikleri yönünden halen ana materyallerinin etkisi altında oldukları saptanmıştır.

\section{Teșekkür}

$\mathrm{Bu}$ çalışma, Türkiye Bilimsel ve Teknoloji Araştırma Kurumu (TÜBİTAK) tarafindan "1180282" nolu proje ile desteklenmiştir.

\section{Kaynaklar}

Anonim, 2011. 1/100.000 Ölçekli Türkiye Jeoloji Haritas1, 158-162 Paftalar. Maden Tetkik ve Arama Genel Müdürlügü (MTA), Ankara.

Anonymous, 1993. Soil Survey Staff. Soil Survey Manual, USDA, Handbook No: 18, Washington D.C.

Anonymous, 1996. Soil Survey Laboratory Methods Manual. Soil Survey Investigations Report No. 42, Version 3.0. United States Department of Agriculture Natural Resources Conservation Service National Soil Survey Center.

Anonymous, 2014a. Soil Taxonomy. A Basic of Soil Classification for Making and Interpreting soil Survey, USDA Handbook No: 436, Washington D.C. USA.

Anonymous, 2014b. World Reference Base for Soil Resources. International Soil Classification System for Naming Soils and Creating Legends for Soil Maps, FAO, World Soil Resoudces Reports No: 106, Rome.

Aydemir, O., Akgül, M., Canbolat, M.Y., Işıldar, A.A., 2001. Toprak Bilgisi. Süleyman Demirel Üniversitesi, Ziraat Fakültesi, Yayın No: 10, Ders Notu Yayın No: 1, Isparta.

Blake, G.R., Hartge, K.H., 1986. Bulk density. In: A. Klute (Ed.), Methods of Soil Analysis, Part 1. Physical and Mineralogical Methods, Agronomy Monograph No: 9, SSSA, Madison, WI, pp. 363375 .

Blakemore, L.C., 1983. Acid-Oxalate Extractable Iron, Aluminuin and Silicon. ICOMAND Circular Letter No: 5, Appendix 1. Intern. Comite' for The Classification of Andisols, New Zealand Soils Bureau, Lower Hutt, New Zealand.

Bouyoucos, G.J., 1951. A Recalibration of the hydrometer method for making mechanical analysis of soil. Agronomy Journal, 43: 434-438.

Dengiz, O., Başkan, O., 2010. Characterizatio of soil profile developmet on differet ladscape in semi-arid region of Turkey, a case study: Ankara-Soğulca catchmet. Anadolu Tarm Bilimleri Dergisi, 25(2): 106-112.

Dengiz, O., Sağlam, M., Özaytekin, H.H., Baskan, O., 2013. Weathering rates and some physico-chemical characteristics of soils developed on a Calcic Toposequences. Carpathian Journal of Earth and Environmental Sciences, 8(2): 13-24.

Duan, L., Hao, J., Xie, S., Zhou Z., Ye, X., 2002. Determining weathering rates of soils in China. Geoderma, 110(3-4): 205-225. 
Erinç, S., 1969. Klimatoloji ve Metodları. İstanbul Üniversitesi, Coğrafya Enstitüsü Yayın No: 35, İstanbul.

Jackson, M.L., 1958. Soil Chemical Analysis. Englewood Cliffs, NJ: Prentice- Hall. Inc.

Jackson, M.L.,1979. Soil Chemical Analysis. Advanced Course, Department of Soil Science, University of Wisconsin, Madison, USA.

Jenkins, D.A., Jones, R.G.W., 1980. Trace elements in rock, soil, plant and animal: Introduction. In: B.E. Davies (Ed.), Applied Soil Trace Elements, John Wiley and Son Ltd., pp. 1-20.

Jeny, H., 1941. Factors of Soil formation. McGraw-Hill, New York.

Harnois, L., 1988. The CIW index: A new chemical index of weathering. Sedimentary Geology, 55(3-4): 319-322.

Hızalan, E., Ünal, H., 1966. Toprakta Önemli Kimyasal Analizler. Ankara Üniversitesi, Ziraat Fakültesi Yayınları: 278, Ankara.

Hodson, M.E., Langan, S.J., Kennedy, F.M., Bain, D.C., 1998. Variation in soil surface area in a chronosequence of soils from Glen Feshie, Scotland and its implications for mineral weathering rate calculations. Geoderma, 85(1): 1-18.

Mutlu, H.H., 2010. Eski Konya Gölü Kuvaterner terasları üzerinde oluşan toprakların jeokimyasal özellikleri ve ayrışma oranları. Yüksek Lisans Tezi, Selçuk Üniversitesi, Fen Bilimleri Enstitüsü, Konya.

Nesbitt, H.W., Young, G.M., 1982. Early Proterozoic climates and plate motions inferred from major element chemistry of lutites. Nature, 299: 715-717.

Özaytekin, H.H., Dedeoğlu, M., 2021. Hasandağ volkanik materyali üzerinde oluşan toprakların ayrışma oranları ve kütle dengesi. Anadolu Tarım Bilimleri Dergisi, 36(1): 81-92.

Özaytekin, H.H., Karakaplan, S., 2012. Soil formation on the Karadağ volcano at a semi arid environment from the Centeral Anatolia. African Journal of Agricultural Research, 7(15): 2283-2296.

Saricaoğlu, S., Dengiz, O., Işik, K., 2021. Assessment of biogeochemical-mineralogical characteristic and weathering indices of soils developed on basaltic parent material and toposequence under subhumid ecosystem. Geomicrobiology Journal, 38(5): 451465.

Schoetzl, R.J., Barrett, L.R., Winkler, J.A., 1994. Choosing models for soil chronofunctions and fitting them to data. European Journal of Soil Science, 45(2): 219-232.

Sparks, B.D., Kotlyar, L.S., O'Carroll, J.B., Chung, K.H., 2003. Athabasca oil sands: effect of organic coated solids on bitumen recovery and quality. Journal of Petroleum Science and Engineering, 39(4): 417-430.

Şenol, H., Dengiz, O., Tunçay, T., 2018. Geochemical mass balance applied to the study of weathering and evolution of soils. Indian Journal of Geo-Marine Science, 47(9): 1851-1865.

Şenol, H., Özaytekin, H.H., Akgül, M., Alaboz, P., 2014. Yarı kurak şartlarda trakit/trakiandezit ana materyal üzerinde oluşan toprakların ayrışma oranları ve kil mineralojisine bakının etkisi. Tarım Bilimleri Dergisi, 20: 288-301.

Şimşek, G., 2000. Toprak Oluşumu (Pedogenesis) ve Sınıflama Ders Notları. Atatürk Üniversitesi, Ziraat Fakültesi Yayınları Ders Notu, Yayın No: 139, Erzurum.

Tunçay, T., Dengiz, O., 2020. The roles of parent material and toposequence on geochemical characteristics and pedogenic iron oxides of soils. Indian Journal of Geo-Marine Science, 49(4): 622623.

Tunçay, T., Dengiz, O., Bayramin, İ., Kılıç, Ş., Başkan, O., 2019. Chemical weathering indices applied to soils developed on old lake sediments in a semi-arid region of Turkey. Eurasian Journal of Soil Science, 8(1): 60-72.

Usul, M., Dengiz, O., 2010. Pedological development of four different parent materials. Anadolu Journal of Agricultural Sciences, 25(S-2): 204-211.

Van Wambeke, A.R., 2000. The Newhall Simulation Model for Estimating Soil Moisture and Temperature Regimes. Department of Crop and Soil Science, Cornell University, Ithaca, NY. 